\title{
Concept paper on SI value assignment of purity - Model for the classification of peptide/protein purity determinations
}

\author{
Ralf D. Josephs ${ }^{* 1}$, Norbert Stoppacher ${ }^{1}$, Steven Westwood ${ }^{1}$, Robert I. \\ Wielgosz ${ }^{1}$, Ming Li $^{2}$, Milena Quaglia ${ }^{3}$, Jeremy Melanson ${ }^{4}$, Gustavo Martos ${ }^{5}$, \\ Desiree Prevoo ${ }^{6}$, Liqing $\mathrm{Wu}^{2}$, Sandra Scapin ${ }^{7}$, Merve Öztug Senal ${ }^{8}$, Lingkai \\ Wong $^{9}$, Ji-Seon Jeong ${ }^{10}$, Kelly Wai Yi Chan ${ }^{11}$, Cristian G. Arsene ${ }^{12}$ and \\ Sang-Ryoul Park ${ }^{10}$ \\ ${ }^{1}$ Bureau International des Poids et Mesures (BIPM), Sèvres, France \\ ${ }^{2}$ National Institute of Metrology (NIM), Beijing, P. R. China \\ ${ }^{3}$ LGC, Teddington, United Kingdom \\ ${ }^{4}$ Measurement Science and Standards, National Research Council (NRC), Ottawa, Canada \\ ${ }^{5}$ Laboratoire National de Métrologie et d'Essais (LNE), Paris, France \\ ${ }^{6}$ National Metrology Institute of South Africa (NMISA), Pretoria, South Africa \\ ${ }^{7}$ National Institute of Metrology, Quality and Technology (INMETRO), Duque de Caxias, \\ Brazil \\ ${ }^{8}$ National Institute of Metrology (TUBITAK UME), Gebze-Kocaeli, Türkiye \\ ${ }^{9}$ Health Science Authority (HSA), Singapore \\ ${ }^{10}$ Korea Research Institute of Standards and Science (KRISS), Daejeon, South Korea \\ ${ }^{11}$ Government Laboratory (GLHK), Kowloon, Hong Kong SAR China \\ ${ }^{12}$ Physikalisch-Technische Bundesanstalt (PTB), Braunschweig, Germany
}

(Received February 6, 2017; Revised February 28, 2017; Accepted March 2, 2017)

\begin{abstract}
Required metrological tools, such as higher order reference measurements procedures, pure substance and matrix certified reference materials, are established for small well defined molecules. Difficulties still remain in the provision of SI traceable standards in the area of larger biomolecules such as peptides/proteins. The provision of Primary Calibration Reference Services has been identified as a core technical competency for National Measurement Institutes (NMIs). A concept has been elaborated by the Focus Group I on peptide/protein purity for the strategic planning of ongoing Key Comparisons of the Protein Analysis Working Group (PAWG) within the Comité Consultatif pour la Quantité de Matière (CCQM). The assignment of the mass fraction content of high purity peptide/protein materials will be the subject of the CCQM-K115/P55.2 comparison series to directly support NMI services and certified reference materials currently being provided by NMIs.
\end{abstract}

Keywords: Peptide; protein; purity; traceability; comparison. (C) 2017 ACG Publications. All rights reserved.

\section{Introduction}

Comparability of (bio)chemical measurements is a prerequisite of any measurement undertaken in support of legislative purposes. For most chemical analysis this can be achieved by

\footnotetext{
* Corresponding author: E-Mail: ralf.josephs@bipm.org; Phone: +33 (0)1 45077070 Fax: +33 (0)1 45342021
} 
ensuring that measurement results are traceable to a known reference such as the base units of the Système International d'Unités (SI). By maintaining such a link, results can be compared over time and space enabling informed decisions to be made and improving our overall knowledge of a subject area. The importance of traceable measurement results can be inferred by its requirement in quality standards (ISO 17025) and in the formation of specialized committees as the Joint Committee on Traceability in Laboratory Medicine (JCTLM). However, whilst the required metrological tools, such as higher order reference measurements procedures, pure substance and matrix certified reference materials, are established for small well defined molecules difficulties still remain in the provision of such standards in the area of larger biomolecules such as peptides/proteins.

\section{Rationale/Purpose}

The approach taken for small molecules relies on Primary Calibrators, often in the form of a synthetic standard of known purity. The provision of Primary Calibration Reference Services has been identified as a core technical competency for National Measurement Institutes (NMIs) in the strategy developed for the planning of ongoing Key Comparisons of the Organic Analysis Working Group (OAWG) within the Comité Consultatif pour la Quantité de Matière (CCQM) [1]. NMIs providing measurement services in organic analysis are expected to participate in a limited number of Track A comparisons that are intended to test and demonstrate their capabilities in this area. Primary Calibration Reference Services refers to a technical capability for composition assignment, usually as the mass fraction content, of organic compound(s) such as pure substances or solutions. The procedure adopted by most NMIs, for the provision of primary pure substance calibrators relies on a mass balance approach. This can be determined either by approaches that measure the mass fraction or mole fraction of the main component directly, or by indirect approaches that identify and estimate the mass fraction of the individual impurities and/or distinct classes of impurities present in the material and, by subtraction, provide a measure for the main component of the material [2]. These approaches have been successfully applied to a large variety of small molecules [3-7].

The quantification of larger molecules is complicated by the fact that they can exhibit higher order structures, and that characterization of the primary structure of the molecule maybe insufficient to correlate the amount of the molecule to its biological activity. Nevertheless, the quantification of the primary structure purity of a larger molecule is the first step in establishing a primary calibrator material for that molecule, where the quantity of interest is the mass fraction of the large molecule. The current discussion is limited to the measurement of the primary structure mass fraction of the molecule within a material.

Another complication for the provision of traceable peptide/protein measurements is that pure peptides/proteins can usually not be obtained in sufficiently large quantities. This has resulted in the harmonization of many large molecule measurements by the provision of accepted practices, methods and/or standards. However, the increased use of targeted hydrolysis based digestion and peptide quantification strategies has enabled the determination of protein amounts via prototypic peptides [810]. These approaches have been investigated for example for the routine analysis of human growth hormone and its biomarkers [11-12]. A number of NMIs have been developing higher order measurement procedures for the analysis of purified protein calibrators [13] and serum based matrix materials [12]. These approaches show great promise for the standardization of priority protein measurands. However, the mass fractions value assignment of proteins (usually larger than $10 \mathrm{kDa}$ ) requires proteotypic peptides of known purity.

The purity of proteotypic peptides and peptides that show direct bioactivity by themselves can be assessed by use of the full mass balance approach. However, a full mass balance approach could require unviably large quantities of peptide material. A simpler alternative to the full mass balance approach is a peptide impurity corrected amino acid (PICAA) analysis, requiring quantification of constituent amino acids (AAs) following hydrolysis of the material and correction for amino acids originating from impurities [14-15]. The general equation for such an approach is given by equation (1), and requires identification and quantification of peptide impurities for the most accurate results. 


$$
x_{\mathrm{P}}=\left(\frac{M_{\mathrm{r}}(\mathrm{P})}{Z_{1}}\right)\left[\frac{n_{\mathrm{AA}}}{m_{\mathrm{m}}}-\sum Y_{\mathrm{IMP}_{i}} \frac{x_{\mathrm{IMP}_{\mathrm{i}}}}{M_{\mathrm{r}}\left(\mathrm{IMP}_{i}\right)}\right]
$$

$x_{\mathrm{P}}$ : mass fraction of peptide in the material

$m_{\mathrm{m}}$ : mass of the material analyzed

$M_{\mathrm{r}}(\mathrm{P})$ : relative molecular mass of peptide

$Z_{1}$ : number of molecules of the AA of interest per peptide molecule

$n_{\mathrm{AA}}$ : amount of substance of the AA of interest measured in the material

$Y_{i}$ : number of molecules of the AA of interest per peptide impurity molecule $\left(\mathrm{IMP}_{\mathrm{i}}\right)$

$x_{\text {IMP } i}:$ mass fraction of the peptide impurity $\operatorname{IMP}_{i}$

$M_{\mathrm{r}}\left(\mathrm{IMP}_{i}\right)$ : relative molecular mass of the peptide impurity $\mathrm{IMP}_{i}$

Traceability of the amino acid analysis results is to pure amino acid certified reference materials (CRMs). Few pure amino acid CRMs are commercially available. Alternatively, traceability could be established through in-house or NMI purity capabilities for amino acids. NMI capabilities to determine the purity of L-valine, were recently assessed in the CCQM-K55.c comparison in the frame of the OAWG [7]. In addition, amino acid analysis and peptide hydrolysis capabilities for the mass concentration assignment of peptide solutions are evaluated in the series of CCQM-P55 comparisons in the framework of the PAWG (and former BAWG) using peptide materials of unknown purity [16].

The application of other approaches for the assessment of peptide purity that require only minor quantities of peptide material is conceivable, for example elemental analysis (CHN/O) with a correction for nitrogen originating from impurities or quantitative nuclear magnetic resonance (qNMR). The BIPM has cross-validated different approaches for the model decapeptide angiotensin I (ANG I) in collaboration with NIST [15] and for the more complex human insulin (hINS).

\section{A model for core competency key comparisons for peptide purity}

The provision of Primary Calibration Reference Services has been identified as a core technical competency for NMIs [17]. It is proposed that NMIs providing measurement services in peptide/protein analysis will in future be expected to participate in a limited number of comparisons that are intended to test and demonstrate their capabilities in this area.

Primary Calibration Reference Services refers to a technical capability for composition assignment, usually as the mass fraction content, of a peptide/protein in the form of high purity solids or standard solutions thereof.

The assignment of the mass fraction content of high purity materials will be the subject of the CCQM-K115/P55.2 comparison [18]. With the aim of leveraging the work required for the CCQMK115/P55.2 comparison and thereby minimizing the workload for NMIs and simultaneously focusing on a material directly relevant to existing $\mathrm{CMC}$ claims, human $\mathrm{C}$ peptide $(\mathrm{hCP})$ is proposed as the most appropriate choice for a study material for a first CCQM key comparison and parallel pilot study looking at competencies to perform peptide purity mass fraction assignment. The BIPM and NIM (China) have co-ordinate this comparison in 2014/2016 [19-20].

Successful participation in this comparison will support Calibration and Measurement Capability (CMC) claims for:

- pure peptide primary reference materials value assigned for the mass fraction of the main component peptide within the material;

- methods for the value assignment of the mass fraction of the main component peptide within the material;

- the identification and quantification of minor component peptide impurities within the material.

It has been proposed that the How Far the Light Shines (HFTLS) statement for the hCP comparison is applicable to chemically synthesized linear peptides of known sequence, without crosslinks, containing up to 31 amino acids. In addition, the comparison will support traceability statements of CMCs for peptide and protein quantification which are dependent on pure peptide reference materials or methods for their value assignment for peptides meeting the above criteria. 


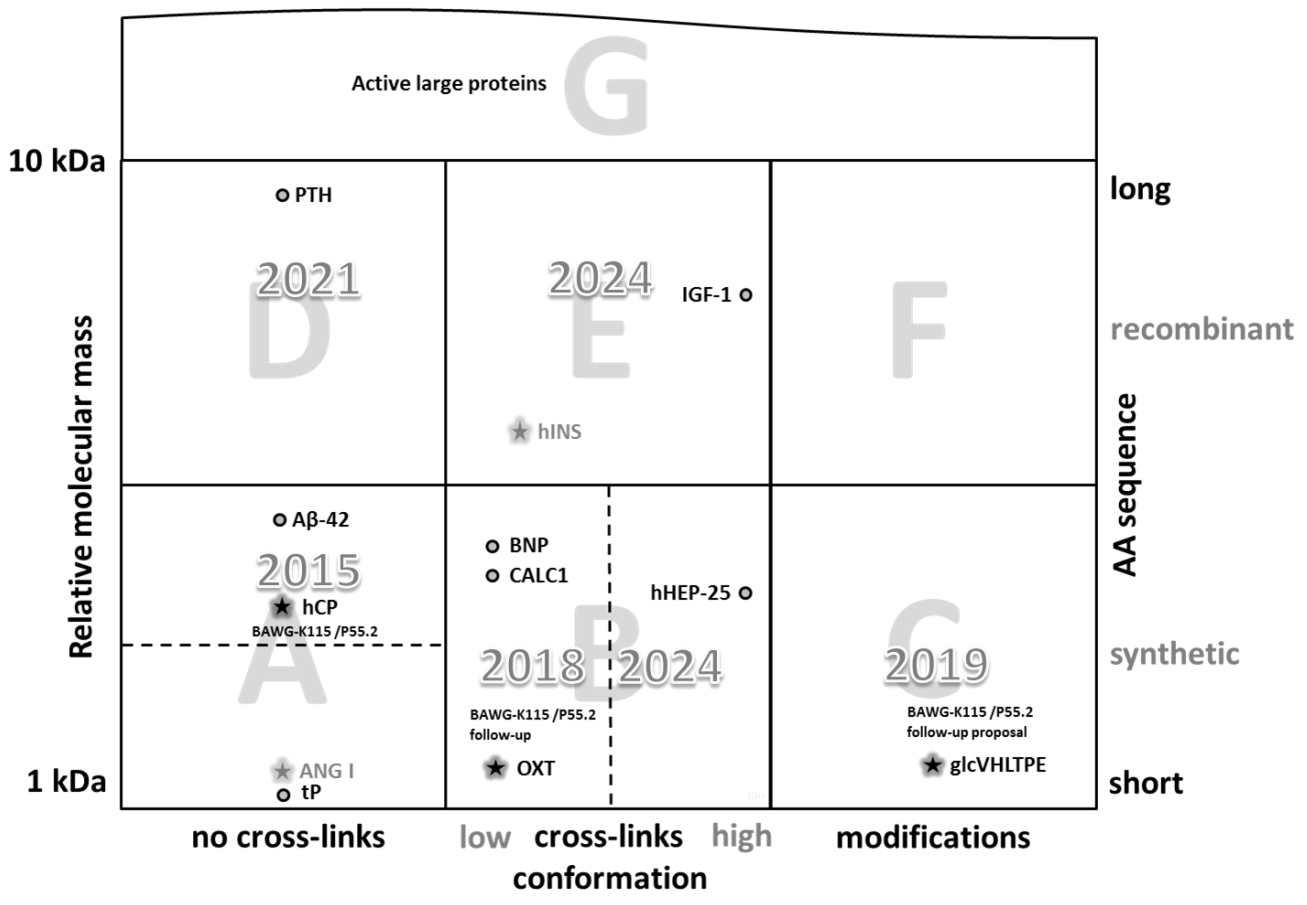

Figure 1. Model for the classification of peptides for primary structure purity determinations

The hCP has been proposed as the comparison material, since:

- it will allow the generic capabilities listed above to be demonstrated for linear peptides without cross-links and of up to 31 amino acids in length;

- it can be obtained in sufficiently large quantities required for the comparison;

- it will directly support NMI services and certified reference materials currently being provided by NMIs [21];

- it is an important analyte for which reference methods have been developed in laboratory medicine [22-25].

However, additional evidence is required to support CMCs related to more complex peptides that contain more than 31 amino acids, or include cross-links, or have been produced using a recombinant process.

In the current paper we propose a model to classify peptides in terms of their relative molecular mass, the amount of cross-linking, and modifications (Figure 1 and Table 1). Based on this classification, we propose that a small number of comparisons can be used to demonstrate NMI capabilities for primary structure purity determinations of all peptides/proteins with a relative molecular mass smaller than $10 \mathrm{kDa}$ (Quadrants A-F). Mass fraction value assignments of proteins larger than $10 \mathrm{kDa}$ are mainly performed by use of proteotypic peptides of known purity (Quadrant G).

The relative molecular mass is the most critical parameter because it is representative for the length of the peptide/protein calibrator. Typically, chromatographic separation identification and quantification of related peptide/protein impurities by mass spectrometric techniques become more challenging for larger peptides/proteins. Larger peptides/proteins are typically associated with a higher statistical probability of the occurrence of more related peptide/protein impurities. Moreover, peptide/protein length has an impact on the hydrolysis method to achieve complete cleavage that is required for reliable quantitative amino acids analysis (PICAA approach). 
Table 1. Detailed information on peptides for the model for the classification

\begin{tabular}{lccc}
\hline Peptide & AAs & kDa & SSs \\
\hline Glycated Hexapeptide of HbA1c (glcVHLTPE) & 6 & $\sim 0.8$ & 0 \\
Tryptic Peptide Solution (tP) & $\sim 10$ & $\sim 1$ & 0 \\
Oxytocin (OXT) & 9 & 1 & 1 \\
Angiotensin I (ANG I) & 10 & 1.2 & 0 \\
Human Hepcidin-25 (hHEP-25) & 25 & 2.8 & 4 \\
Human C-Peptide (hCP) & 31 & 3 & 0 \\
Calcitonin Salmon (CALC1) & 32 & 3.4 & 1 \\
Brain Natriuretic Peptide (BNP) & 32 & 3.5 & 1 \\
Amyloid-Beta-42 (Aß-42) & 42 & 4.5 & 0 \\
Human Insulin (hINS) & 51 & 5.8 & 3 \\
Insulin-like Growth Factor 1 (IGF-1) & 70 & 7.6 & 3 \\
Parathyroid Hormone (PTH) & 84 & 9.4 & 0 \\
\hline
\end{tabular}

In practice, the coupling efficiency of amino acids in peptide synthesis decreases significantly with the formation of longer peptides/proteins. Synthetic pure (proteotypic) calibrator peptides/proteins are typically shorter than 75 amino acids. In addition, peptide/protein stability decreases and purification of peptides/proteins that are produced by recombinant techniques becomes more laborious for longer peptides/proteins. Hence, a relative molecular mass limit of $10 \mathrm{kDa}$ was established for the model.

Cross-linking is another key parameter of the model. Cross-links stabilize specific conformations of peptides/proteins. The important steps of identification and quantification of related peptide/protein impurities by mass spectrometric techniques are more difficult if one or more crosslinks are present. Peptide/protein cross-links are mainly represented by intra- or intermolecular disulfide bonds.

Modifications of peptides/proteins signify a further important parameter of the model. A modification, for example glycation of a peptide/protein can play an important role if the ratio of the glycated and non-glycated form of a peptide/protein is specific for a disease state (biomarker). If modifications are present both identification and quantification of related peptide/protein impurities by mass spectrometric techniques are more difficult as well.

The degree of difficulty for the purity characterization of peptide/protein calibrators is supposed to increase from quadrant A to $G$ (Figure 1) because of the increasing lengths of the molecules and incorporation of peptide/protein cross-links and modifications.

In addition, it has to be specified if the pure (proteotypic) calibrator peptides/proteins has been synthesized or if it was obtained by purification of recombinant produced more complex peptides/proteins. Synthetic (proteotypic) pure calibrator peptides/proteins will typically fit in the lower space (Quadrants A-C). While more complex calibrators that are commonly produced by recombinant techniques will usually be part of in the upper space (Quadrants D-G).

The actual, follow-up and follow-up proposal CCQM-K115/P55.2 comparisons for hCP, oxytocin (OXT) and glycated hexapeptide of HbA1c, respectively (stars marked in black) and other peptides of current interest to NMIs (circles marked in black) are indicated in the model for the classification of peptides for primary structure purity determinations (Figure 1 and Table 1). The model is limited to peptides/proteins of up to $10 \mathrm{kDa}$ with the assumption that mass fractions value assignments of larger proteins are commonly performed using proteotypic peptides of known purity that are covered by the model of for the classification of peptides (Quadrant $\mathrm{G}$ ).

CCQM-K115/P55.2 on hCP covers the space of quadrant A for short (1 kDa to $5 \mathrm{kDa})$, noncross-linked, non-modified synthetic peptides. This comparison has been proposed after validation work was carried out by the BIPM and the NIST on angiotensin I (ANG I) that also fits in the space of quadrant A (stars marked in grey). Future studies need to be designed to address the other three quadrants of the model.

The next CCQM-K115/P55.2 follow-up study on oxytocin (OXT) accepted by PAWG for 2018 will cover the space of quadrant $\mathrm{B}$ for short $(1 \mathrm{kDa}$ to $5 \mathrm{kDa}$ ), cross-linked and non-modified synthetic peptides. OXT is a nine amino acid residue cyclic peptide. It is a hormone, neuropeptide and active pharmaceutical compound (API) used to induce labor or to enhance uterine contractions during 
labor. OXT is one of the peptide hormones that is increasingly frequent prepared synthetically to avoid possible contamination with vasopressin $(\mathrm{ADH})$ and other small polypeptides with biologic activity.

A third CCQM-K115/P55.2 study on glycated hexapetide of HbA1c (glcVHLTPE) proposed within PAWG for 2019 covers the space of quadrant $\mathrm{C}$ for short ( $1 \mathrm{kDa}$ to $5 \mathrm{kDa}$ ), non-cross-link but modified peptides. The measurement of the stable glucose adduct HbA1c in human blood is most important for the long-term control of the glycaemic state in diabetic patients. HbAlc can be measured as ratio between the glycated (glcVHLTPE) and non-glycated hexapeptide (VHLTPE) [26-27].

In addition, the BIPM has completed a project on human insulin (hINS) purity characterization. The hINS is a model peptide/protein with a relative molecular mass in the (5k Da to $10 \mathrm{kDa}$ range) and multiple cross-links representing peptides/proteins of quadrant $\mathrm{E}$ (stars marked in grey).

The Focus Group I of the PAWG, NMIs and other experts are regularly asked to identify potential peptide/protein calibrator candidates of interest to them and to populate the quadrants of the model in the near future.

A number of other peptides of interest to NMIs are also plotted within the model:

- amyloid-beta (A $\beta-40$ and $\mathrm{A} \beta-42)$ [1 kDa to $5 \mathrm{kDa}$ range and 0 cross-links];

- short synthetic tryptic (proteotypic) peptide (tP) $[1 \mathrm{kDa}$ to $5 \mathrm{kDa}$ range and 0 crosslinks];

- parathyroid hormone (PTH) [5 $\mathrm{kDa}$ to $10 \mathrm{kDa}$ range and 0 cross-links];

- hepcidins (hHEP-20 and hHEP-25) [1 kDa to $5 \mathrm{kDa}$ range and 4 cross-links];

- insulin-like growth factor 1 (IGF-1) [5 kDa to $10 \mathrm{kDa}$ range and 3 cross-links].

The amyloid beta peptides $(A \beta-40$ and $A \beta-42)$ are neurotoxic and play a role as Alzheimer's disease biomarkers. They are synthetic candidates for future studies that would fit in the space of quadrant A.

Short synthetic (proteotypic) tryptic peptides (tP) covering the value assignment of corresponding larger proteins are further candidates for studies that typically would be covered by quadrant $\mathrm{A}$.

The parathyroid hormone (PTH) is a hyperparathyroidism biomarker. It is secreted by the chief cells of the parathyroid glands and acts to increase the concentration of calcium in the blood. It is a candidate that would cover the space of quadrant D. A CCQM-K115/P55.2 follow-up study covering quadrant D could be envisaged for 2021.

The hepcidins (hHEP-20 and hHEP-25) are liver-specific antimicrobial peptides and iron-regulatory hormones. They could be potential recombinant candidates representing peptides/proteins of quadrant B. hHEP has been investigated by the BIPM/LNE [28]. It has not only the difficulty of multiple cross-links but also occurs in several isobaric higher order structures that would lead to a kind of 'conformational purity'. However, identification, separation and quantification of the isobaric higher order structures require additional technologies that are still immature and rarely available within NMIs. Therefore, compounds as hHEP are separated by a dotted line in quadrant B and proposed as study candidates at a later stage (not before 2024).

Insulin-like growth factor 1 (IGF-1) plays an important role in childhood growth and continues to have anabolic effects in adults. It is a typical larger recombinant candidate representing peptides/proteins of quadrant E. A CCQM-K115/P55.2 follow-up study addressing quadrant D could be envisaged for 2024 .

If possible comparisons should be carried out by use of pure solid peptide/protein materials to obtain a maximum of information. However, comparisons on mass concentration measurements of pure solutions could be contemplated if the peptide/protein is of utmost interest and its availability very limited. 


\section{References}

[1] L. Mackay (2013). CCQM OAWG Strategy Document for Rolling Programme Development, OAWG/1302, BIPM webpage, CCQM OAWG working documents.

[2] S. Westwood, T. Choteau, A. Daireaux, R. D. Josephs and R. I. Wielgosz (2013). Mass balance method for the SI value assignment of the purity of organic compounds, Anal. Chem. 85, 3118-3126.

[3] S. Westwood, R. D. Josephs, T. Choteau, A. Daireaux, C. Mesquida, R. I. Wielgosz, A. Rosso, M. Ruiz de Arechavaleta, S. Davies, H. Wang, E C. Pires do Rego, J. Marques Rodrigues, E. de Freitas Guimarães, M. V. Barreto Sousa, T. M. Monteiro, L. Alves das Neves Valente, F. G. Marques Violante, R. R. Ribeiro Almeida, M. C. Baptista Quaresma, R. Nogueira, A. Windust, X. Dai, X. Li, W. Zhang, M. Li, M. Shao, C. Wei, S.-K. Wong, J. Cabillic, F. Gantois, R. Philipp, D. Pfeifer, S. Hein, U.-A. Klyk-Seitz, K. Ishikawa, E. Castro, N. Gonzalez, A. Krylov, T. Tang Lin, L. Tong Kooi, M. Fernandes-Whaley, D. Prévoo, M. Archer, R. Visser, N. Nlhapo, B. J. de Vos, S. Ahn, P. Pookrod, K. Wiangnon, N. Sudsiri, K. Muaksang, C. Cherdchu, A. C. Gören, M. Bilsel, T. LeGoff, D. Bearden, M. Bedner, D. Duewer, D. Hancock, B. Lang, K. Lippa, M. Schantz and J. Sieber (2012). Final report on key comparison CCQM-K55.b (Aldrin): An international comparison of mass fraction purity assignment of Aldrin, Metrologia 49, Tech. Suppl., 1A, 08014.

[4] S. Westwood, R. D. Josephs, A. Daireaux, R. I. Wielgosz, S. Davies, H. Wang, J. Rodrigues, W. Wollinger, A. Windust, M. Kang, S. Fuhai, R. Philipp, P. Kuhlich, S.-K. Wong, Y. Shimizu, M. Pérez, M. Avila, M. Fernandes-Whaley, D. Prevoo, B. J. de Vos, R. Visser, M. Archer, T. LeGoff, S. Wood, D. Bearden, M. Bedner, A. Boroujerdi, D. Duewer, D. Hancock, B. Lang, B. Porter, M. Schantz, J. Sieber, E. White and S. A. Wise (2012). Final report on key comparison CCQM-K55.a (Estradiol): An international comparison of mass fraction purity assignment of estradiol, Metrologia 49, Tech. Suppl., 1A, 08009.

[5] S. Westwood, R. D. Josephs, T. Choteau, C. Mesquida, A. Daireaux, R. I. Wielgosz, S. Davies, A. Windust, M. Kang, H. Ting, K. Kato, E. Frias, M. Pérez, P. Apps, M. Fernandes-Whaley, K. Wiangnon, N. Ruangrittinon, S. Wood, T. LeGoff, D. Duewer, M. Schantz, L. Siekmann and J. Esker (2011). An international comparison of mass fraction purity assignment of digoxin: CCQM Pilot Study CCQM-P20.f (Digoxin), Metrologia 48, Tech. Suppl., 1A, 08013.

[6] S. Westwood, R. D. Josephs, A. Daireaux, R. I. Wielgosz, S. Davies, M. Kang, H. Ting, R. Phillip, F. Malz, Y. Shimizu, E. Frias, M. Pérez, P. Apps, M. Fernandes-Whaley, B. J. de Vos, K. Wiangnon, N. Ruangrittinon, S. Wood, D. Duewer, M. Schantz, M. Bedner, D. Hancock and J. Esker (2009). An international comparison of mass fraction purity assignment of theophylline: CCQM Pilot Study CCQMP20.e (Theophylline), Metrologia 46, Tech. Suppl., 1A, 08019.

[7] S. Westwood, R. D. Josephs, T. Choteau, A. Daireaux, R. Wielgosz, S. Davies, M. Moad, B. Chan, A. Muñoz, P. Conneely, M. Ricci, E. C. Pires do Rego, B. C. Garrido, F. G. M. Violante, A. Windust, X. Dai, T. Huang, W. Zhang, F. Su, C. Quan, H. Wang, M.-F. Lo, W.-F. Wong, F. Gantois, B. Lalere, U. Dorgerloh, M. Koch, U.-A. Klyk-Seitz, D. Pfeifer, R. Philipp, C. Piechotta, S. Recknagel, R. Rothe, T. Yamazaki, O. B. Zakaria, E. Castro, M. Balderas, N. González, C. Salazar, L. Regalado, E. Valle, L. Rodríguez, L. Á. Laguna, P. Ramírez, M. Avila, J. Ibarra, L. Valle, M. Pérez, M. Arce, Y. Mitani, L. Konopelko, A. Krylov, E. Lopushanskaya, T. T. Lin, Q. Liu, L. T. Kooi, M. Fernandes-Whaley, D. PrevooFranzsen, N. Nhlapo, R. Visser, B. Kim, H. Lee, P. Kankaew, P. Pookrod, N. Sudsiri, K. Shearman, A. C. Gören, G. Bilsel, H. Yilmaz, M. Bilsel, M. Çergel, F. G. Çoskun, E. Uysal, S. Gündüz, I. Ün, J. Warren, D. W. Bearden, M. Bedner, D. L. Duewer, B. E. Lang, K. A. Lippa, M. M. Schantz and J. R. Sieber (2014). Final report on key comparison CCQM-K55.c (L-(+)-Valine): Characterization of organic substances for chemical purity, Metrologia 51, Tech. Suppl., 1A, 08010.

[8] C. Pritchard, F. A. Torma, C. Hopley, M. Quaglia and G. O’Connor (2011). Investigating microwave hydrolysis for the traceable quantification of peptide standards using gas chromatography-mass spectrometry, Anal. Biochem. 412, 40-46.

[9] C. Pritchard, M. Quaglia, C. Mussell, W. I. Burkitt, H. Parkes and G. O'Connor (2009). Fully traceable absolute protein quantification of somatropin that allows independent comparison of somatropin standards, Clin. Chem. 55, 1984-1990.

[10] W. I. Burkitt, C. Pritchard, C. Arsene, A. Henrion, D. Bunk and G. O’Connor (2008). Toward Systeme International d'Unite-traceable protein quantification: From amino acids to proteins, Anal. Biochem. 376, 242-251.

[11] C. G. Arsene, R. Ohlendorf, W. Burkitt, C. Pritchard, A. Henrion, G. O'Connor, D. M. Bunk and B. Guettler (2008). Protein Quantification by Isotope Dilution Mass Spectrometry of Proteolytic Fragments: Cleavage Rate and Accuracy, Anal. Chem. 80, 4154-4160.

[12] C. G. Arsene, A. Henrion, N. Diekmann, J. Manolopoulou and M. Bidlingmaier (2010). Quantification of growth hormone in serum by isotope dilution mass spectrometry. Anal Biochem. 401, 228-235.

[13] A. Munoz, R. Kral and H. Schimmel (2011). Quantification of protein calibrants by amino acid analysis using isotope dilution mass spectrometry, Anal. Biochem. 408, 124-131. 
[14] N. Stoppacher, R. D. Josephs, A. Daireaux, S. Westwood and R. I. Wielgosz (2013). Impurity identification and determination for the peptide hormone angiotensin I by liquid chromatography - high resolution tandem mass spectrometry and the metrological impact on value assignments by amino acid analysis, Anal. Bioanal. Chem. 405, 8039-8051.

[15] R. D, Josephs, N, Stoppacher, A, Daireaux, T, Choteau, K. A. Lippa, K. Phinney, S. Westwood and R. I. Wielgosz (2017). State-of-the-art and Trends for the SI Traceable Value Assignment of the Purity of Peptides Using the Model Compound Angiotensin I., Trends Anal. Chem. [submitted].

[16] D. Bunk (2012). P55.1 Scope of applicability BAWG/12-54 and Hydrolysis investigation study BAWG/1259, BIPM webpage, CCQM BAWG working documents.

[17] J. Marriott, G. O'Connor and H. Parkes (2011). Final Report - Study of Measurement Service and Comparison Needs for an International Measurement Infrastructure for the Biosciences and Biotechnology: Input for the BIPM Work Programme. Rapport BIPM-2011/02, http://www.bipm.org/utils/common/pdf/rapportBIPM/2011/02.pdf

[18] R. D. Josephs, M. Li, H. Li and R. I. Wielgosz (2013). CCQM-K115/P55.2: Key Comparison on Peptide Purity: Protocol Proposal (NIM and BIPM) PAWG-K115/P55.2 and OAWG/13-43, BIPM webpage, CCQM BAWG/OAWG working documents.

[19] R. D. Josephs, M. Li, D. Song, S. Westwood, N. Stoppacher, A. Daireaux, T. Choteau, R. I. Wielgosz, P. Xiao, Y. Liu, X. Gao, C. Zhang, T. Zhang, W. Mi, C. Quan, T. Huang, H. Li, R. Flatschart, R. Borges Oliveira, J. E. Melanson, R. Ohlendorf, A. Henrion, T. Kinumi, L. Wong, Q. Liu, M. Oztug Senal, B. Vatansever, I. Ün, A. C. Gören, M. Akgöz, M. Quaglia and J. Warren (2017). Final Report on key comparison CCQM-K115: Peptide Purity - Synthetic Human C-Peptide, Metrologia 54, Tech. Suppl., 1A, 08007.

[20] R. D. Josephs, M. Li, D. Song, A. Daireaux, T. Choteau, N. Stoppacher, S. Westwood, R. I. Wielgosz, H. Li, J. E. Melanson, M. Akgöz, A. C. Gören, I. Ün, M. Quaglia and J. Warren (2017). Final report on pilot study CCQM-P55.2: Peptide purity - Synthetic human C-peptide, Metrologia 54, Tech. Suppl., 1A, 08011.

[21] T. Kinumi, M. Goto, S. Eyama, M. Kato, T. Kasama and A. Takatsu (2012). Development of SI-traceable C-peptide certified reference material NMIJ CRM 6901-a using isotope-dilution mass spectrometry-based amino acid analyses, Anal. Bioanal. Chem. 404, 13-21.

[22] R. R. Little, C. L. Rohlfing, A. L. Tennill, R. W. Madsen, K. S. Polonsky, G. L. Myers, C. J. Greenbaum, J. P. Palmer, E. Rogatsky and D. T. Stein (2008). Standardization of C-peptide measurements, Clin. Chem. 54, 1023-1026.

[23] C. Fierens, D. Stöckl, D. Baetens, A. P. De Leenheer and L. M. Thienpont (2003). Application of a Cpeptide electrospray ionization-isotope dilution-liquid chromatography tandem mass spectrometry measurement procedure for the evaluation of five C-peptide immunoassays for urine, J. Chromatogr. B. 792, 249-259.

[24] D. Rodriguez-Cabaleiro, D. Stöckl and L. M. Thienpont (2005). Improvement of sample pretreatment prior to analysis of C-peptide in serum by isotope dilution-liquid chromatography-tandem mass spectrometry, Rapid Commun. Mass Spectrom. 19, 3600-3602.

[25] D. Rodríguez-Cabaleiro, D. Stöckl, J. M. Kaufman, T. Fiers and L. M. Thienpont (2006). Feasibility of Standardization of Serum C-Peptide Immunoassays with Isotope-Dilution Liquid ChromatographyTandem Mass Spectrometry, Clin. Chem. 52, 1193-1196.

[26] P. Kaiser, T. Akerboom, P. Molnar and H. Reinauer (2008). Modified HPLC electrospray ionization/mass spectrometry method for HbA1c based on IFCC reference measurement procedure, Clin. Chem. 54, 10181022.

[27] P. Kaiser, T. Akerboom and R. Ohlendorf (2010). Liquid chromatographyisotope dilution-mass spectrometry as a new basis for the reference measurement procedure for hemoglobin. Liquid chromatography-isotope dilution-mass spectrometry as a new basis for the reference measurement procedure for hemoglobin A1c determination, Clin. Chem. 56, 750-754.

[28] P. Bros, R. D. Josephs, N. Stoppacher, G. Cazals, S. Lehmann, C. Hirtz, R. I. Wielgosz and V. Delatour (2017). Impurity determination for hepcidin by liquid chromatography - High resolution and ion mobility mass spectrometry for the value assignment of candidate primary calibrators, Anal. Bioanal. Chem. [in press, online: http://rd.springer.com/article/10.1007/s00216-017-0202-4.

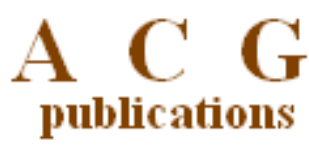

(C) 2017 ACG Publications 